\title{
THE INFLUENCE OF NATIONAL CULTURE ON KNOWLEDGE MANAGEMENT IN CHINA MANAGERIAL IMPLICATIONS FOR CENTRAL EUROPEAN COUNTRIES
}

\author{
Kubátová, J.
}

\begin{abstract}
Together with the ever increasing economic position of China, the importance of understanding the specifics of Chinese national culture and their influence on knowledge management, or on the management of Chinese knowledge workers, is also increasing. The objective of this article is to present the most important specifics of Chinese national culture and clarify their influence on the behavior and ways of work of Chinese knowledge workers. The second objective is to sum up some managerial implications for managers from Central European Countries (CEC) - Austria, Czech Republic, Germany, Hungary, Poland, Slovakia, Slovenia, and Switzerland. Methodologically, this article is based upon Hofstede's characteristics of cultural dimensions and their application on China. Also, an analysis of case studies from the Chinese environment has been used and comparison to Western approaches to knowledge management and knowledge workers performed. The article shall prepare managers for cooperation with their Chinese partners while emphasizing that this cooperation will be interesting, though absolutely not easy, since the Chinese approach to knowledge and its sharing under the influence of their national culture is very specific and different from Western ways. The term "Western cultures" is understood to mean namely the cultures of Europe and the U.S.A. (Hofstede, 2007); thus, CEC is a part of Western culture.
\end{abstract}

JEL Classification: M12

\section{Introduction}

Knowing the main characteristics of a national culture helps one understand why people from different parts of the world behave differently. "Culture is the collective programming of the human mind that distinguishes the members of one human group from those of another. Culture, in this sense, includes a system of collectively held values" (Hofstede, 1984, p. 21).

Hofstede has denoted his own definition of culture as incomplete but defends it by saying that culture, or its main characteristics, can be measured according to this definition. Certain values, which determine general tendencies of members of a particular culture to prefer certain states of reality to others, are the core of every culture. Values, which are specific for individual countries, can be statistically grouped. Groups of values which arise from this are denoted as the dimensions of a national culture (Hofstede, 2012). Hofstede originally worked with only four dimensions: Power Distance (measured using the Power Distance Index, PDI), Individualism versus Collectivism (measured using the Individualism Index, IDV), Masculinity versus Femininity (measured using the Masculinity Index, MAS), and Uncertainty Avoidance (measured using the Uncertainty Avoidance Index, UAI). Subsequently, the Long-Term Orientation dimension (measured using the LTO index) was added, and in 2010 Hofstede added the Indulgence versus Restraint dimension (measured using the IVR index).

Hofstede and his colleagues created an extensive methodology of measuring individual indexes (Hofstede, 2001; Hofstede and Hofstede, 2005, Hofstede et al. 2010). Index values range from 0 to 120 on the scale. Index value for a specific country indicates how strong a specific tendency there is; the higher the index value, the stronger the tendency is. 
Chart 1: Cultural dimensions of CEC and China

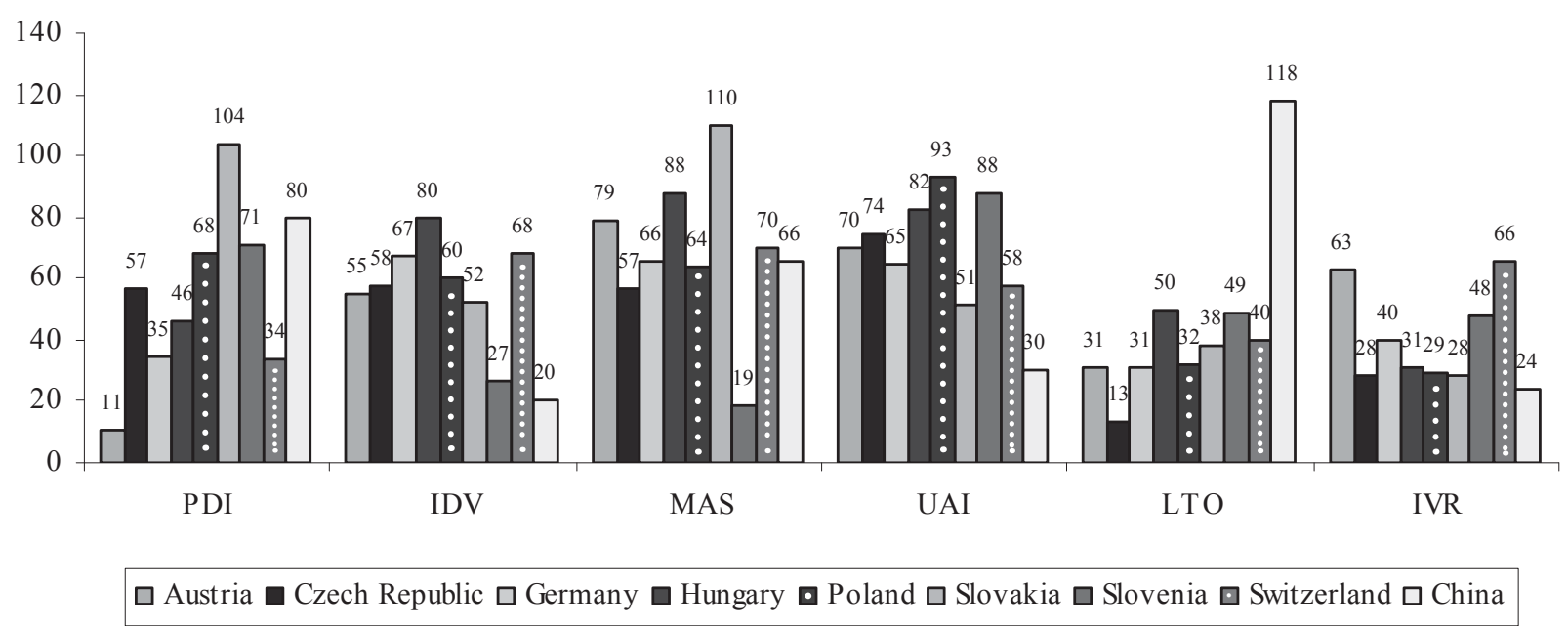

Source: Hofstede et al. 2010, Hofstede, 2012

The Power Distance dimension, or the PDI value, indicates to what extent hierarchical and power differences are accepted in the given country, and how much members of the culture respect mutual inequalities. People in cultures with a high PDI accept the hierarchical order in which each member has their own given place. In cultures with a low PDI, people strive to achieve a balanced social and power status; natural respect toward people in higher social and power positions cannot be expected here.

The Individualism versus Collectivism dimension, or the IDV index, expresses the extent of the importance of social relationships in a society. A high value of IDV suggests that people consider themselves responsible mainly for themselves and their closest family. That is why they have a tendency to carry through their individual interests. A low value of IDV appears in cultures where a strong emphasis is placed on group (either a work group or wider family). Individuals put a stronger emphasis on the interests of the groups in which they belong, rather than on their personal interests. In exchange for this, their group provides them with support and aid.

The Masculinity versus Femininity dimension, or the MAS index, expresses the inclination of a culture to values which are traditionally considered to be masculine/feminine. By masculine values Hofstede means, for example, focus on performance, heroism, assertiveness, and the expectation of a material reward for one's performance. Competitiveness can be seen within such a culture. On the other hand, feminine values lie in the tendency to cooperate, reach an agreement, moderateness, caring for the weaker members of the society, and overall focus on the quality of life and environment.

The Uncertainty Avoidance dimension, or the UAI, expresses the extent up to which members of the society are willing to undergo and cope with risk and uncertainty. Societies with a high UAI have a tendency to create systems of strict rules which are supposed to reduce uncertainty in respect to future development. On the contrary, societies with a low UAI have a tendency to accept events as they come, and address them once they occur.

The Long-term versus Short-term Orientation dimension, or the LTO index, relates to the perception of the importance of time and traditions. Societies with a high value of the LTO index include in their decision-making process long-term perspectives, have a tendency to save and invest, the people are persistent in achieving their objectives. These cultures also acknowledge that circumstances change in the course of time and that is why it is natural for them to change their decisions. Societies with a low LTO index focus on achieving short-time goals. In their behavior they rely on traditions which they consider immutable. They do not have a tendency to project conceptions of a more distant future into their decisions.

The Indulgence versus Restraint dimension, or the IVR index, expresses a tendency of the society to enjoy life on the one hand and/or to create stringent rules of behavior on the other. Societies which respect free demonstrations of the human desire for the pleasures of life have 
a high IVR index. Societies, where respected behavior is subject to stringent social norms and open indulgence is not tolerated, have a low IVR index. Chart 1 shows a comparison of values of the individual indexes of CEC and China.

It is evident that in comparison with CEC, China has extremely strong long-term orientation, a very low level of individualism, a relatively high power distance index and a low uncertainty avoidance index. Differences in cultural dimensions can help when we estimate how workers from different national cultures might behave. However, this is not enough in case of China. This problem is explained in the following sections of this article.

\section{Methods}

In the beginning of the text we explained, using Hofstede‘s approach, the terms national culture, cultural dimensions, their importance for effective management of people, and presented Chart 1 comparing Chinese and CEC cultural dimensions for illustration. In the following part of the text, based on secondary research and an analysis of case studies, we present the roots and elements of Chinese national culture, which have a vital influence on the behavior of Chinese knowledge workers and knowledge management in China. A synthesis of the acquired findings has enabled us to make recommendations, the application of which can contribute to an easier and faster establishment of cooperation with Chinese colleagues. By a final comparison of Chinese and Western cultural values we have established those values, which are common for both these cultures, and that is why we recommend them as basic for the management of knowledge workers in either culture.

\section{Roots and elements of Chinese culture}

Chinese culture is based on four basic roots which have cemented Chinese inhabitants for five thousand years, and therefore they are logically demonstrated in their conduct and work behavior (Graham and Lam, 2003).

Agrarian values (agrarianism) are the first root. Two-thirds of Chinese people live in rural areas and subsist on agriculture. Success depends on group cooperation, obedience and subordination to family hierarchy as well as on harmony and respecting the laws of nature. Traditional agriculture has also given rise to the belief among the Chinese that agriculture represents the roots of the society and trade represents its branches. Thus, farmers traditionally enjoyed greater respect than traders. The second root of Chinese national culture is morality.
This tendency of the Chinese society reinforces a generally well-known Confucius` teaching. Confucius taught that only a society which follows moderate moral rules can be stable, prosper and cannot be jeopardized by any attacks. In the society, these rules are enforced by way of a respected hierarchy, in which there are clear relations of superiority and subordination. In addition to this, a traditional Taoist belief claims that nothing can be explained one-sidedly, but holistically. For example, nothing is only good or bad but everything contains both elements, so the lump cannot be denoted as either good or bad. Thus the Chinese do not only care about the result itself, but also about the way they have achieved it. Finding the way is just as important to them as the goal. That is why they do not look for quick solutions but spend as much time searching for a way to them as they deem appropriate.

Another root of Chinese culture is the above-mentioned holistic thinking, conditioned by Chinese picture writing. They embrace everything holistically so they try and capture all the aspects of a problem at once. It is difficult to orient in such an approach for members of different cultures.

The last root is Chinese caution toward foreigners, which has developed on the basis of long historical experience of China. Trust is absolutely fundamental for any sort of cooperation in China. The truth is that winning someone's trust is a very long process, while losing it may be instantaneous and permanent.

\section{Eight elements of Chinese culture}

Eight basic elements of Chinese culture which influence methods of cooperation with the Chinese can be identified. We have organized them in order of their importance to knowledge management in intercultural teams containing Chinese people.

\section{Personal Connections (Guanxi)}

The importance of personal relationships or social capital is generally accepted, so at first sight China is no different from other cultures in this respect. However, the explanation of the term Guanxi, meaning personal relationships or social capital, is incomplete. Guanxi takes a very long time to create; a brief acquaintance is not enough. In order to create Guanxi, people must know each other for a long time, know each other in private, there must be trust between them, and the principle of reciprocity must work also. People who have Guanxi do each other favors which must always be returned. Failing to return a favor means the end of a relationship and is considered highly immoral. 
In China, Guanxi is decisive for sharing knowledge. Rendering knowledge is a favor.

\section{The Intermediary (Zhongjian Ren)}

Acquiring Guanxi, which means penetrating the existing social structure, is very difficult for newcomers, especially if they are foreigners. The whole process can only be sped up in case a newcomer has a mediator who has contacts among the people with whom the newcomer wants to cooperate. This feature of the Chinese culture is known as Zhongjian Ren and translated as the Intermediary. It is very suitable if the intermediary is a Chinese because he/she may help a foreign rookie interpret the behavior of the Chinese party.

\section{Face (Mianzi)}

The principle of Mianzi is closely tied to Guanxi. In China, you can have, acquire, lose or give face. Face is the most important gauge of an individual's social status. It can be described as the prestige and dignity of an individual. The sources of Mianzi are namely status, wealth, abilities, intelligence and also good Guanxi. There are many ways how to acquire or lose face, and they unwind from Chinese moral principles and traditions. The Chinese behave in order not to cause a loss of face not only to themselves, but also their partners. This may give rise to many misunderstandings while dealing with the Chinese and that is why it is useful to have the above-mentioned intermediary by your side who can help interpret Chinese behavior. A loss of face, for example, may occur if you show emotions while dealing with the Chinese, especially negative ones. A loss of face will also occur in case of a direct refusal. A Chinese, in order not to offend a colleague, will never give him/her an explicitly negative answer, but an evasive answer, which might suggest hope for a positive outcome. Open criticism or admonition also means a loss of face. From the position of knowledge work the biggest problem, however, lies in the fact that the Chinese respect hierarchy. In their culture it is unthinkable that they could propose a solution to a problem. For example, if the leader of a team wants to use brainstorming, the Chinese will make a passive impression. It is not because they do not want to or know how to solve the problem, but it is unacceptable to them to propose their idea. On a team containing also members of individualistic cultures who are, on the contrary, usually very active, the Chinese will not express themselves without sensitive support from the team leader. Sensitive support means repeated calls for a proposal and the ability to decipher the answer, since this will probably be conveyed metaphorically to make sure it does not sound like advice to the team leader. Advising higher-positioned colleagues is considered impolite and even insulting in China. The Chinese behave similarly when they discover that someone else has made a mistake. Either they quietly rectify it because the result of the whole team's work is important to them, or if they do not have this possibility, they do not call attention to it since by doing so they would insult the person who made the mistake. As we have mentioned before, it is necessary to avoid having a Chinese colleague lose his/her face as a result of our behavior. It is a catastrophe which cannot be rectified and which means a complete interruption of relationships. It may happen, though, that the person who caused the loss of face is not even aware of that, and will be surprised that the affected colleague has started shunning him/her, will not answer his/her phone calls, will not reply to his/her e-mails, etc.

\section{Interpersonal harmony (Renji Hexie)}

The Chinese strive to achieve harmony in interpersonal relationships; this is why they put so much emphasis on saving their face as well as other people's face. In this effort, they are assisted by the respected hierarchical organization of the society, which explicitly determines the status of individuals. Chinese behavior does not contain negative emotions. On the contrary, smiling courtesy is expected. This principle blends with the fact that in order to create Guanxi, it is necessary that the individuals know each other not only on a professional but also on a private basis. Generally speaking, it is characteristic for China that professional and private lives fade into each other. Within Renji Hexie, the Chinese devote a long time to getting to know their partners really well, to learn as much as possible about them, and only then do they start to trust them and establish cooperation with them.

\section{Social Status (Shehui Dengji)}

It has been repeatedly stated that China is a typically hierarchical society and it is necessary for foreigners cooperating with the Chinese to respect this fact. It means that it is necessary to create teams in such a way that the Chinese could regard their colleagues as their peers from this point of view. In China, for example, a person's prestige increases with age. Therefore there will likely be a problem if a team leader is much younger than other Chinese team members. The Chinese might regard such a situation as a loss of face, despite the fact that they generally respect a higher hierarchical position of leading workers. At the same time though, they expect the person who holds such a position to have achieved it 
through an appropriately long period of time gathering experience.

\section{Holistic thinking (Zhengti Guannian)}

From the point of view of sharing knowledge, the difference between Chinese entirety thinking and Western sequential thinking is essential (and very difficult to imagine). The Western way of thinking lies in decomposing the situation into partial, logical and concurring sections, which are addressed in succession. A correctly led meeting has a pre-set plan during which individual points are discussed, it is short and has a clear output. The Chinese approach a situation as a whole and address it in all possible contexts, from various points of view, and all that repeatedly. They repeatedly open questions which had already seemed solved, address them again and in a different way. Many issues are being discussed at the same time; meetings take a long time and are repeated over and over again. As mentioned above, not only the result is important to the Chinese, but also the way to achieve it.

\section{Thrift (Jiejian)}

Whatever activity the Chinese are involved in, they try and conserve financial costs. Their propensity to thrift affects their conduct and decision making. They can negotiate for a long time in terms of financial costs. It is good to know that if you help a Chinese party save money, you give them face by doing so, and you win face too. Moreover, you can expect reciprocity from the Chinese party. It is one of the possible ways to acquire Guanxi.

\section{Endurance, Eating Bitterness (Chilku Nailao)}

The Chinese are persistent and tenacious, they are also very diligent and prepared to endure even very demanding conditions, and they appreciate it if their colleagues have these qualities too. Their endurance is also reflected in the fact that they do not save time, the way they save money. They do not understand the saying "Time is money". They are proud of their long history, and in comparison to it nothing seems too long to them. Therefore, they are willing to devote themselves to working on any task for as long as they deem appropriate, which might make representatives of Western cultures nervous. However, demonstrations of impatience may lead to losing face.

\section{Other specifics of the approach to knowledge in China}

In the part of the world which we refer to as Western culture (including CEC), knowledge management is developed as a theoretical and practical discipline. Information from knowledge management and knowledge workers is summarized in the monograph "Management of Knowledge Workers" by Ludmila Mládková (Mládková, 2012). Management of knowledge workers in the Western concept quite understandably builds on the principles of Western cultures which, even if necessarily simplified, are a low Power Distance Index and a high level of Individualism. This means that there is not a very significant hierarchical structure in organizations, the manager - worker position is not respected too strictly, the team leader is accepted as a colleague who mainly supports and coordinates team cooperation. Workers are independent, actively propose their suggestions of solving tasks, and take part in team work. Thus, in Western culture it is possible to apply principles of effective management of knowledge workers, which are based on the principles of autonomy and independence of workers. In China, however, the situation is different. If we want to penetrate it at least a little bit, we have to study some cultural specifics which affect the perception of the importance of knowledge in this country.

Passing on knowledge in China is influenced by a long historical experience which says that ensuring a living for oneself and their family is tied to a unique ability, which the others lack but need. Craftsmen developed and carefully saved their abilities in order to successfully develop their trade. Thus it became natural in China to protect one's knowledge and share it only in a limited manner and after careful consideration. In China, knowledge is still perceived also as a source of power, which is demonstrated in families, companies, and this approach can be perceived also in national politics. Both knowledge and information are generally highly appreciated in China. Knowledge sharing in companies is not determined only by the fact that workers cooperate on the same project or are in a different organizational relationship. The Chinese naturally respect company hierarchy in which a manager is perceived by his/her subordinates as more experienced, more knowledgeable and wiser, therefore the subordinates do not dare actively present their proposals. We do not encounter free and open knowledge exchange in China. Before it occurs, it must be clear that the act will be reciprocal. We can detect here a general tendency of the Chinese to do each other favors, however, always on the principle of reciprocity. In this respect, the way the Chinese view acquiring someone else's knowledge because the owner failed to protect it sufficiently, is very interesting. In China, such a behavior is not considered as theft of intellectual property but fortune. 
In companies it is difficult to find people who might have the necessary knowledge. Not even during company meetings can you expect that knowledge will be freely passed on. Regarding meetings, especially in case of newly-composed teams, it is necessary to calculate with a long time of getting to know each other. Establishing personal relationships is a primary prerequisite for subsequent cooperation. The way meetings are led is also conditioned by the above-mentioned holistic thinking of Chinese society. The important thing still is that if we do not belong in the right structure, we will not acquire the necessary knowledge, even in a meeting.

The importance of Guanxi in the Chinese society has been explained. Persons with Guanxi share knowledge more willingly. If someone does not have Guanxi, they have no other choice than create it first, in order to be able to share knowledge later. The principles of Guanxi and Mienzi in Chinese society have given rise to another phenomenon, which is strongly demonstrated in companies and affects the availability of knowledge. This phenomenon is called Quanzi. Quanzi simply means personal network. It is demonstrated through the origin of very strong structures of individuals within or outside a company. These individuals primarily have Guanxi and subsequently create Quanzi. Quanzi does not copy company hierarchy and it is possible that a manager with a higher hierarchical position does not belong in Quanzi, and thus does not have access to some knowledge. On the contrary, workers at lower hierarchical levels may, thanks to Quanzi, gain direct access to top management. Also persons who are not employees of the given company but have both the knowledge and influence (e.g. members of local governments) belong in Quanzi. The existence of Quanzi may not even be noticeable from the outside, as well as it is often impossible to distinguish, who belongs in this (usually) very powerful network. Quanzi is a big obstacle to sharing knowledge effectively.

\section{Managerial Implications}

In case of cooperation with the Chinese, there is basically no other choice than to know the specifics of Chinese national culture and count on the fact that they affect the thinking and ways of working of Chinese colleagues. Even if young Chinese people with education from Western universities have a bit closer attachment to Western practices, we cannot assume that they would adapt to Western ways. On the contrary, the Chinese are great patriots and are proud of their culture. What can a manager from a Central European country do to strengthen sharing knowledge? The easiest thing he/she can do is to compare the cultural dimensions of their own country to those of China. As Chart 1 shows, the differences vary for each country; however, this does not tell us everything. Managers also have to consider the above-mentioned roots and elements of Chinese culture. These roots and elements are included in a Guanxioriented model of human resources management by Law and Jones (Law and Jones, 2009). However, adopting such an approach to managing knowledge workers cannot be only the question of theoretical training but a continuous acquisition of experience. If a manager wants to apply a Guanxi-oriented model of managing knowledge workers, he/she should adhere to five basic rules which respect the specifics of Chinese national culture:

- Chinese thinking is holistic; therefore, nothing is distinctively good or bad, everything contains both these elements.

- Development is dynamic, everything changes and it is necessary to adapt to the development.

- Everything is interconnected, each impulse has many demonstrations.

- Things are unpredictable, it is necessary to be flexible; changing decisions that have been made also means flexibility.

- Every favor must be returned within a certain period of time; sharing knowledge is also considered a favor.

If we think about these briefly outlined principles of managing workers on the principle of Guanxi, we can see a striking similarity to Western principles of holistic thinking, which are upheld also in Western cultures including CEC (Suff and Reily, 2005). The reason might be that a basic prerequisite for sharing knowledge and cooperation in all cultures is mutual trust. This trust, however, arises and disappears in Western cultures in a different way and faster than in China, but its importance is comparable. Thus we can arrive at the conclusion that despite all the cultural differences between CEC and China, some common values may be found upon which successful management of knowledge workers can be built.

\section{These values are:}

- Respect of knowledge, skills and talent. In CEC, as well as in China, skilled and talented knowledge workers are the main competitive advantage of companies. They are highly motivated if the managers show respect for their human capital. 
- Trust. People who do not trust each other usually are not willing to share and create knowledge together. Thus the managers have to support establishment and development of trust on their teams.

- Tolerance. Knowledge workers are usually outstanding individuals with their own ways of work. Managers have to tolerate their habits and trust that they do their best.

- Kindness and reciprocity. Kindness should be one of the most important company values if the company is serious in terms of its knowledge management. A kind and pleasant atmosphere is one of the crucial conditions for creative knowledge work. Managers determine and disseminate the atmosphere in the company and they have to be aware of it.

- Justice. Justice is a basic need of employees. Workers are willing to share knowledge if they feel that they are treated fairly. Managers have to continuously examine if their coworkers are satisfied in this respect. If they are frustrated, their willingness to apply their knowledge in favor of their company will decrease.

The aim of this article was to highlight some differences in behavior of Central European and Chinese knowledge workers and explain their causes. Knowledge management theory which is prevalent in Central Europe usually does not cover the specifics of Chinese national culture and their influence on knowledge sharing and creation. We have found some values and principles which are common to all cultures. The application of these values and principles in knowledge workers management can increase their motivation to share knowledge.

\section{References}

Graham, J. L., Lam, M. N. (2003). The Chinese Negotiation. Harvard Business Review. OnPoint Article, Harward Business School Publishing Corporation.

Hofstede, G. (1984). Culture's Consequences: International Differences in Work-Related Values. Thousand Oaks: Sage.

Hofstede, G. (2001). Culture's Consequences: comparing values, behaviors, institutions, and organizations across nations (2nd ed.). Thousand Oaks: Sage.

Hofstede, G. National cultural dimensions. (accessed April 29, 2012), [available at http://geert-hofstede.com/nationalculture.html].

Hofstede, G. (2007) Asian management in the $21^{\text {st }}$ century. Asia Pacific Journal of Management, 24: 411-420.

Hofstede, G.; Hofstede, G. J. (2005). Cultures and organizations: software of the mind (Revised and expanded 2nd ed.). New York: McGraw-Hill.

Hofstede, G.; Hofstede, G. J., Minkov, M. (2010). Cultures and organizations: software of the mind. Third Edition. New York: McGraw-Hill.

Law, S. F., Jones, S. (2009). A Guanxi Model of Human Resource Management. Chinese Management Studies, 3(4): 313-327.

Mládková, L. (2012). Management of Knowledge Workers. Bratislava: Iura Edition.

Suff, P., Reily P. (2005). In the Know: Reward and Performance Management of Knowledge Workers. Brighton: Institute for Employment Studies.

Author

Ass. Prof. Jaroslava Kubátová, Ph.D. Head of the Department of Applied Economics, Palacky University in Olomouc Philosophical Faculty, Kř́žkovského 12, 77180

Olomouc, Czech Republic jaroslava.kubatova@upol.cz 